\title{
Efficacy and Safety of Canagliflozin in Patients with Type 2 Diabetes and Stage 3 Nephropathy
}

\author{
Hala Yamout ${ }^{a}$ Vlado Perkovic ${ }^{d}$ Melanie Davies ${ }^{e}$ Vincent Woo ${ }^{f}$ \\ Dick de Zeeuw $^{g}$ Cristiana Mayer ${ }^{\mathrm{b}}$ Ujjwala Vijapurkar ${ }^{c}$ Irina Kline ${ }^{c}$ \\ Keith Usiskin ${ }^{c}$ Gary Meininger ${ }^{c}$ George Bakris ${ }^{a}$ \\ ${ }^{a}$ The University of Chicago Medicine, Chicago, Ill., Janssen Research \& Development, LLC, b Titusville and \\ ${ }^{\mathrm{C}}$ Raritan, N.J., USA; ${ }^{\mathrm{d}}$ George Institute for Global Health, Sydney, N.S.W., Australia; ${ }^{\mathrm{e}}$ University of Leicester,

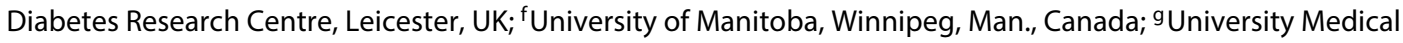 \\ Centre Groningen, Groningen, The Netherlands
}

\section{Key Words}

Diabetes $\cdot$ Kidney $\cdot$ Nephropathy $\cdot$ Hypertension

\begin{abstract}
Background/Aims: Some sodium glucose co-transporter 2 (SGLT2) inhibitors are approved for the treatment of patients with type 2 diabetes mellitus (T2DM) with an estimated glomerular filtration rate (eGFR) of $\geq 45 \mathrm{ml} / \mathrm{min} / 1.73 \mathrm{~m}^{2}$. The efficacy and safety of canagliflozin, an approved SGLT2 inhibitor, was evaluated in patients with stage 3 chronic kidney disease (CKD; eGFR $\geq 30$ to $<60 \mathrm{ml} / \mathrm{min} / 1.73 \mathrm{~m}^{2}$ ). Methods: This analysis used integrated data from four randomized, placebo-controlled, phase 3 studies that enrolled patients with T2DM and stage 3 CKD. Results are presented for the overall population as well as subgroups with stage $3 a$ CKD (eGFR $\geq 45$ and $<60 \mathrm{ml} / \mathrm{min} / 1.73 \mathrm{~m}^{2}$ ) and stage $3 \mathrm{~b}$ CKD (eGFR $\geq 30$ and $<45 \mathrm{ml} / \mathrm{min} / 1.73 \mathrm{~m}^{2}$ ). Results: Among all subjects studied with stage $3 \mathrm{CKD}$, placebo-subtracted reductions in $\mathrm{HbA}_{1 \mathrm{c}}(-0.38$ and $-0.47 \% ; \mathrm{p}<0.001)$, body weight $(-1.6$ and $-1.9 \% ; p<0.001)$, and systolic blood pressure $(-2.8$ and -4.4 $\mathrm{mm} \mathrm{Hg} ; \mathrm{p}<0.01$ ) were seen with canagliflozin 100 and 300 $\mathrm{mg}$, respectively. Decreases in $\mathrm{HbA}_{1 c}$, body weight, and sys-
\end{abstract}

\begin{tabular}{ll}
\hline KARGER & $\begin{array}{l}\text { ( 2014 S. Karger AG, Basel } \\
0250-8095 / 14 / 0401-0064 \$ 39.50 / 0\end{array}$ \\
$\begin{array}{l}\text { E-Mail karger@karger.com } \\
\text { www.karger.com/ajn }\end{array}$ & $\begin{array}{l}\text { This is an Open Access article licensed under the terms of the } \\
\text { Creative Commons Attribution-NonCommercial 3.0 Un- } \\
\text { ported license (CC BY-NC) (www.karger.com/OA-license), } \\
\text { applicable to the online version of the article only. Distribu- } \\
\text { tion permitted for non-commercial purposes only. }\end{array}$
\end{tabular}

tolic blood pressure were examined in the stage $3 \mathrm{a}$ and $3 \mathrm{~b}$ CKD subgroups, with greater decreases in $\mathrm{HbA}_{1 c},-0.47 \%$ $(-0.61,-0.32)$ and body weight in subjects in stage $3 a$ CKD, $-1.8 \%(-2.3,-1.2)$ with canagliflozin $100 \mathrm{mg}$. Initial declines in eGFR were seen early following treatment initiation with canagliflozin, but trended towards baseline over time. The most common adverse events with canagliflozin included genital mycotic infections and adverse events related to reduced intravascular volume likely secondary to osmotic diuresis. Conclusion: In subjects with T2DM and stage 3 CKD, canagliflozin reduced $\mathrm{HbA}_{1 \mathrm{c}}$, body weight, and blood pressure, and was generally well tolerated. @ 2014 S. Karger AG, Basel

\section{Introduction}

Chronic kidney disease (CKD) is a common complication in patients with type 2 diabetes mellitus (T2DM), with up to $30 \%$ of patients developing stage 3 or higher $\mathrm{CKD}$ (estimated glomerular filtration rate $(\mathrm{eGFR})<60$ $\mathrm{ml} / \mathrm{min} / 1.73 \mathrm{~m}^{2}$ ) within 15 years of diagnosis $[1,2]$. Management of T2DM in patients with CKD represents a clin-

George Bakris, MD, FASH, FASN

ASH Comprehensive Hypertension Center

The University of Chicago Medicine

5841 S. Maryland Ave, MC 1027 Chicago, IL 60637 (USA)

E-Mail gbakris@gmail.com 
Table 1. Study design and subject description ${ }^{\mathrm{a}}$

\begin{tabular}{|c|c|c|c|c|c|c|c|c|}
\hline \multirow[t]{2}{*}{ Study } & \multirow[t]{2}{*}{$\begin{array}{l}\text { Duration }{ }^{\mathrm{b}} \text {, } \\
\text { week }\end{array}$} & \multicolumn{3}{|c|}{ Inclusion criteria } & \multicolumn{4}{|c|}{$\begin{array}{l}\text { Subjects contributing data to } \\
\text { pooled analysis, } \mathrm{n}\end{array}$} \\
\hline & & age, years & $\mathrm{HbA}_{1 \mathrm{c}}, \%$ & $\begin{array}{l}\mathrm{eGFR} \\
\mathrm{ml} / \mathrm{min} / 1.73 \mathrm{~m}^{2}\end{array}$ & $\mathrm{PBO}$ & $\begin{array}{l}\text { CANA } \\
100 \mathrm{mg}\end{array}$ & $\begin{array}{l}\text { CANA } \\
300 \mathrm{mg}\end{array}$ & total \\
\hline $\begin{array}{l}\text { Monotherapy } \\
\text { CANagliflozin cardioVascular }\end{array}$ & 26 & $\geq 18$ to $\leq 80$ & $\geq 7.0, \leq 10.0$ & $\geq 50$ & 10 & 10 & 12 & 32 \\
\hline Older adults & 26 & $\geq 55$ to $\leq 80$ & $\geq 7.0, \leq 10.0$ & $\geq 50$ & 35 & 33 & 26 & 94 \\
\hline Overall total, $\mathrm{n}$ & & & & & 382 & 338 & 365 & 1,085 \\
\hline
\end{tabular}

$\mathrm{PBO}=$ Placebo; CANA = canagliflozin .

${ }^{a}$ Key exclusion criteria in common across the studies included repeated FPG $>15.0 \mathrm{mmol} / \mathrm{l}$ (270 mg/dl) in general during the pretreatment phase; history of T1DM, CV disease (including myocardial infarction, unstable angina, revascularization procedure, or cerebrovascular accident) within 3 months prior to screening; or alanine aminotransferase (ALT) level $>2.0$ times the upper limit of normal (ULN) or total bilirubin $>1.5$ the ULN at screening. ${ }^{b}$ Primary efficacy assessment time point.

ical challenge with limited treatment options, as most oral hypoglycemic agents have decreased efficacy and/or delayed clearance as well as more adverse events (AEs) among those with stage 3 or higher CKD $[1,3]$. A novel class of oral agents, sodium glucose co-transporter 2 (SGLT2) inhibitors, provide physicians with an additional treatment option for patients with T2DM and stage 3 CKD.

The SGLT2 protein, expressed in the proximal tubules of the kidney, is responsible for about $90 \%$ of glucose reabsorption filtered through the glomerulus $[4,5]$. Filtered glucose is almost fully reabsorbed until the transporters reach maximum glucose capacity; the plasma concentration at which this occurs is referred to as the renal threshold for glucose $\left(\mathrm{RT}_{\mathrm{G}}\right)$. Above this threshold, urinary glucose excretion increases in proportion to the plasma glucose concentration.

Canagliflozin is an orally active SGLT2 inhibitor developed for the treatment of patients with T2DM [6-13]. By inhibiting SGLT2, canagliflozin lowers $\mathrm{RT}_{\mathrm{G}}$, resulting in increased glycosuria and osmotic diuresis, thus directly lowering plasma glucose concentrations in patients with elevated glucose levels $[9,14-16]$. Increased urinary glucose excretion also results in weight loss due to loss of calories as well as reductions in blood pressure (BP) likely secondary to the osmotic diuresis. Moreover, while canagliflozin lowers $\mathrm{RT}_{\mathrm{G}}$ in patients with $\mathrm{T} 2 \mathrm{DM}$ to approximately $4.4-5.5 \mathrm{mmol} / \mathrm{l}(80-100 \mathrm{mg} / \mathrm{dl})[9,14]$, it is above the usual threshold for hypoglycemia $(\leq 3.9 \mathrm{mmol} / \mathrm{l}$ $(70 \mathrm{mg} / \mathrm{dl}))$, hence the risk of hypoglycemia with canagliflozin is relatively low. This paper provides analysis of pooled data from all clinical trials that evaluated the safety and efficacy of canagliflozin in subjects with T2DM and stage 3 CKD.

\section{Materials and Methods}

Study Design, Patient Populations, and Treatments

Data were pooled from the cohorts enrolled in four randomized, placebo-controlled, phase 3 studies of subjects with T2DM with a baseline eGFR $\geq 30$ and $<60 \mathrm{ml} / \mathrm{min} / 1.73 \mathrm{~m}^{2}$ [17]. The studies included in this analysis are summarized in table 1 and include data from the canagliflozin monotherapy study [18], a study in subjects with T2DM and stage $3 \mathrm{CKD}$ (with baseline eGFR $\geq 30$ and $<50 \mathrm{ml} / \mathrm{min} / 1.73 \mathrm{~m}^{2}$ ) [13], a study in older subjects (aged 55-80) [6], and the ongoing CANagliflozin cardioVascular Assessment Study (CANVAS, interim data provided for regulatory filing) [19]. Due to the lack of a control group, data from subjects in the high glycemic subset $\left(\mathrm{HbA}_{1 \mathrm{c}}>10.0\right.$ and $\left.\leq 12.0 \%\right)$ of the monotherapy study were excluded from this analysis.

Across studies, eligible subjects included men and women with T2DM who had inadequate glycemic control at screening while on protocol-specified diabetes treatment regimens (diet and exercise for the monotherapy study and any approved agent for the other three studies). Patient inclusion and exclusion criteria and details of the individual study designs have previously been reported [6, $13,18,19]$.

In CANVAS and the study in older subjects, those meeting enrollment criteria entered a 2 -week, placebo run-in period prior to randomization. In the monotherapy and stage $3 \mathrm{CKD}$ studies, subjects who were not on protocol-specified background diabetes therapy or were on an anti-hyperglycemic agent (AHA) regimen not consistent with local prescribing information at screening, respectively, entered an AHA adjustment (or washout for the monotherapy study)/dose stable period prior to the placebo run-in period to meet study-specific criteria. In each study, subjects were 
randomly assigned to receive once daily oral doses of canagliflozin 100 or $300 \mathrm{mg}$ or placebo. In all studies, randomization was stratified to ensure adequate distribution of specific patient characteristics across treatment groups as previously reported $[6,13,18,19]$. $\mathrm{HbA}_{1 \mathrm{c}}$, fasting plasma glucose (FPG), and postprandial glucose values were masked to study centers following randomization unless $\mathrm{HbA}_{1 \mathrm{c}}$ and FPG values met pre-specified glycemic criteria for initiation of rescue therapy. Databases were locked at the primary assessment time point for each study, and studies were unblinded by the sponsor for regulatory filing; subjects and study center and local sponsor personnel remained blinded through completion of the respective double-blind treatment periods of each study.

Patients were to remain on stable diabetes treatment (diet/exercise and AHA regimen) throughout the double-blind treatment period. Those meeting pre-specified glycemic criteria were provided with rescue therapy (with metformin, monotherapy study, and uptitration of current AHAs or stepwise addition of other AHAs for CANVAS and studies in stage 3 CKD subjects and older subjects). In general, during the double-blind treatment period, glycemic rescue therapy was initiated if FPG $>15.0 \mathrm{mmol} / \mathrm{l}(270$ $\mathrm{mg} / \mathrm{dl})$ after day 1 to week $6,>13.3 \mathrm{mmol} / \mathrm{l}(240 \mathrm{mg} / \mathrm{dl})$ after week 6 to week 12 , and $>11.1 \mathrm{mmol} / \mathrm{l}(200 \mathrm{mg} / \mathrm{dl})$ after week 12 to week 26. For CANVAS, patient's glycemic goals and the need for adjustment in the AHA regimen were to be determined by the investigator after week 18. The mean duration of drug exposure in this trial was approximately 36 weeks, slightly longer in the canagliflozin groups compared to placebo.

All studies included in this analysis were conducted in accordance with ethical principles that comply with the Declaration of Helsinki and are consistent with Good Clinical Practice and applicable regulatory requirements. Institutional review boards at participating institutions approved study protocols and amendments. All subjects provided written informed consent prior to participation.

\section{Study Endpoints and Assessments}

Efficacy endpoints were evaluated at the primary assessment time point for each study (week 26 for the 3 studies and week 18 for CANVAS). Endpoints included change from baseline in $\mathrm{HbA}_{1 \mathrm{c}}$ and the proportion of subjects achieving $\mathrm{HbA}_{1 \mathrm{c}}<7.0 \%$; change from baseline in FPG and systolic and diastolic BP; percent change from baseline in body weight (reported for data prior to rescue therapy).

Safety analyses included data up to week 26 for the monotherapy, stage $3 \mathrm{CKD}$, and older cohort studies, and a cutoff date of at least 18 weeks for CANVAS. Overall safety and tolerability were evaluated based on AE reports, safety laboratory tests, 12-lead electrocardiograms, vital sign measurements, self-monitored blood glucose, and physical examinations. Specific attention was given to AEs related to osmotic diuresis and reduced intravascular volume that may be associated with lower eGFR values. Pre-specified queries were constructed for each of these AEs using lists of Medical Dictionary for Regulatory Activities (MedDRA) preferred terms consistent with the AE of interest; terms associated with each $\mathrm{AE}$ were grouped for analysis.

Documented hypoglycemia episodes, including biochemically documented episodes (concurrent fingerstick or plasma glucose $\leq 3.9 \mathrm{mmol} / \mathrm{l}(70 \mathrm{mg} / \mathrm{dl})$ irrespective of symptoms) and severe hypoglycemia episodes (i.e. requiring the assistance of another individual or resulting in seizure or loss of consciousness), were also evaluated. Given the potential effect of background AHAs on the risk of hypoglycemia, incidences of documented hypoglycemia are reported separately for subjects who were, or were not, on background AHA therapy associated with hypoglycemia (e.g. insulin, sulfonylureas).

Percent changes from baseline in fasting plasma lipids (i.e. triglycerides, low-density lipoprotein cholesterol (LDL-C), highdensity lipoprotein cholesterol (HDL-C), LDL-C/HDL-C ratio, and non-HDL-C) were evaluated. Laboratory safety assessments included blood chemistry (e.g. serum creatinine, eGFR), hematology, urinalysis, and urine albumin/creatinine ratio (ACR). Data for change in urine ACR are reported for the individual studies in subjects with stage $3 \mathrm{CKD}$ and CANVAS. For evaluation of other clinical laboratory analyses, the proportion of subjects meeting predefined limits of change criteria was assessed based on any post-baseline measurement and on the last on-treatment measurement (defined as the last value within 2 days after the last dose of study medication).

\section{Statistical Methods}

Efficacy analyses were conducted using the modified intent-totreat population, which consisted of all randomized subjects who received $\geq 1$ dose of study drug, according to the randomized treatment assignment. The last observation carried forward (LOCF) approach was used to impute missing efficacy data. If subjects received rescue therapy, all post-rescue data were censored and the last post-baseline value prior to the initiation of rescue therapy was used for analyses. Continuous efficacy endpoints were assessed using an analysis of covariance (ANCOVA) model with treatment and study as factors and the respective baseline value as a covariate. Least squares (LS) mean differences and two-sided 95\% confidence intervals (CIs) were estimated based on this model for the comparison of each canagliflozin group versus placebo with no multiplicity adjustment.

A sensitivity analysis of the change from baseline in $\mathrm{HbA}_{1 \mathrm{c}}$ was also performed using the completers analysis set (i.e. subjects in the pooled population who completed the study through the primary assessment time point) using the same analysis approach. The categorical efficacy endpoint (i.e. proportion of subjects achieving $\mathrm{HbA}_{1 \mathrm{c}}$ goals) was analyzed using a logistic regression model with treatment and study as factors and baseline $\mathrm{HbA}_{1 \mathrm{c}}$ as covariate.

Safety analyses were performed in randomized subjects who received $\geq 1$ dose of study drug. All AEs and lipids parameters are reported for regardless of rescue therapy; documented hypoglycemia episodes are reported for prior to rescue medication.

\section{Results}

\section{Baseline Characteristics}

The baseline demographic characteristics were similar among the treatment arms as listed in table 2. While the data represent a cross section of ethnic groups, there are lower percentages of some groups. Nevertheless, across all phase 3 studies in the canagliflozin program $(\mathrm{n}=$ 10,285 randomized subjects who had taken at least one dose of the study medication), the majority of the Black 
Table 2. Baseline demographic and disease characteristics (total stage $3 \mathrm{CKD}$ cohort)

\begin{tabular}{|c|c|c|c|}
\hline Characteristic & $\begin{array}{l}\mathrm{PBO} \\
(\mathrm{n}=382)\end{array}$ & $\begin{array}{l}\text { CANA } 100 \mathrm{mg} \\
(\mathrm{n}=338)\end{array}$ & $\begin{array}{l}\text { CANA } 300 \mathrm{mg} \\
(\mathrm{n}=365)\end{array}$ \\
\hline \multicolumn{4}{|l|}{ Sex, n (\%) } \\
\hline Female & $156(41)$ & $140(41)$ & $155(42)$ \\
\hline Mean age $\pm S D$, years & $66.9 \pm 7.6$ & $67.3 \pm 8.1$ & $66.9 \pm 7.4$ \\
\hline \multicolumn{4}{|l|}{ Race, $\mathrm{n}(\%)^{\mathrm{a}}$} \\
\hline Black or African-American ${ }^{\mathrm{b}}$ & $9(2)$ & $9(3)$ & $13(4)$ \\
\hline Asian & $50(13)$ & $43(13)$ & $48(13)$ \\
\hline Other ${ }^{\mathrm{c}}$ & $14(4)$ & $26(8)$ & $24(7)$ \\
\hline Mean body mass index $\pm \mathrm{SD}, \mathrm{kg} / \mathrm{m}^{2}$ & $33.0 \pm 6.2$ & $32.2 \pm 6.1$ & $32.3 \pm 6.1$ \\
\hline Mean triglycerides $\pm \mathrm{SD}, \mathrm{mmol} / \mathrm{l}$ & $2.1 \pm 1.3$ & $2.0 \pm 1.1$ & $2.0 \pm 1.0$ \\
\hline Mean LDL-C \pm SD, mmol/l & $2.4 \pm 0.9$ & $2.3 \pm 0.9$ & $2.3 \pm 1.0$ \\
\hline Daily cigarette smoker at study entry, n (\%) & $45(11.8)$ & $32(9.5)$ & $33(9.0)$ \\
\hline Patients on AHA at baseline, $\mathrm{n}(\%)$ & $365(95.5)$ & $321(95.0)$ & $346(94.8)$ \\
\hline Biguanide $^{\mathrm{d}}$ & $147(38.5)$ & $111(32.8)$ & $107(29.3)$ \\
\hline Sulfonylurea $^{\mathrm{d}}$ & $160(41.9)$ & $128(37.9)$ & $141(38.6)$ \\
\hline Insulin $^{\mathrm{d}}$ & $219(57.3)$ & $208(61.5)$ & $221(60.5)$ \\
\hline Patients on antihypertensive medication at baseline, $\mathrm{n}(\%)^{\mathrm{e}}$ & $345(90.3)$ & $307(90.8)$ & $326(89.3)$ \\
\hline ACE inhibitor & $191(50.0)$ & $146(43.2)$ & $164(44.9)$ \\
\hline $\mathrm{ARB}$ & $131(34.3)$ & $120(35.5)$ & $121(33.2)$ \\
\hline ACE inhibitor + ARB & $18(4.7)$ & $20(5.9)$ & $17(4.7)$ \\
\hline ACE inhibitor + diuretic & $8(2.1)$ & $18(5.3)$ & $12(3.3)$ \\
\hline $\mathrm{ARB}+$ diuretic & $14(3.7)$ & $16(4.7)$ & $20(5.5)$ \\
\hline
\end{tabular}

$\mathrm{PBO}=$ Placebo CANA = canagliflozin.

a Percentages may not total $100 \%$ due to rounding. ${ }^{b}$ Black/African-American patients represent $10 \%$ (30/299) of patients with stage 3 CKD from the USA. ${ }^{c}$ Includes American-Indian or Alaska Native, Native Hawaiian or other Pacific Islanders, multiple, other, not reported, and unknown. ${ }^{\mathrm{d}}$ Alone or in combination with other AHAs. ${ }^{\mathrm{e}}$ ACE inhibitor or ARB or diuretic.

or African-American subjects were recruited from the USA and represent approximately $14 \%(359 / 2634)$ of the subjects randomized from the USA, consistent with the proportion having T2DM in the USA in this population. Note that the studies discussed in this analysis did not mandate a pre-specified breakdown of racial and ethnic representation, however the data are consistent with the proportion of African-Americans having T2DM in the USA.

Evaluation of subgroups based on eGFR showed that those with stage $3 \mathrm{~b}$ CKD were older and had a longer mean duration of T2DM as compared to those with stage 3a CKD, although $\mathrm{HbA}_{1 \mathrm{c}}$ was similar in both subgroups (online suppl. table 1; for all online suppl. material, see www.karger.com/doi/10.1159/000364909). Those with stage $3 \mathrm{a}$ CKD had a mean \pm SD baseline eGFR of $53.3 \pm$
$4.2 \mathrm{ml} / \mathrm{min} / 1.73 \mathrm{~m}^{2}$ compared to those with stage $3 \mathrm{~b}$ CKD who had a mean GFR of $38.2 \pm 4.1 \mathrm{ml} / \mathrm{min} / 1.73 \mathrm{~m}^{2}$. Overall, $90.1 \%$ of subjects were receiving either an angiotensin-converting enzyme (ACE) inhibitor, angiotensin receptor blocker (ARB), or a diuretic; $88.1 \%$ of those with stage 3a CKD were on these medications, as were $94.2 \%$ of those with stage $3 \mathrm{~b} C K D$.

\section{Efficacy}

Total Cohort of Subjects with Stage 3 CKD

In the overall cohort of subjects with stage $3 \mathrm{CKD}$, significant reductions in $\mathrm{HbA}_{1 \mathrm{c}}$ were seen with canagliflozin 100 and $300 \mathrm{mg}$ relative to placebo (LS mean differences $(95 \% \mathrm{CI})$ of $-0.38 \%(-0.50,-0.26)$ and $-0.47 \%(-0.60$, $-0.35)$, respectively; $p<0.001$; fig. 1a). Results of the sensitivity analysis using the completers analysis set showed 


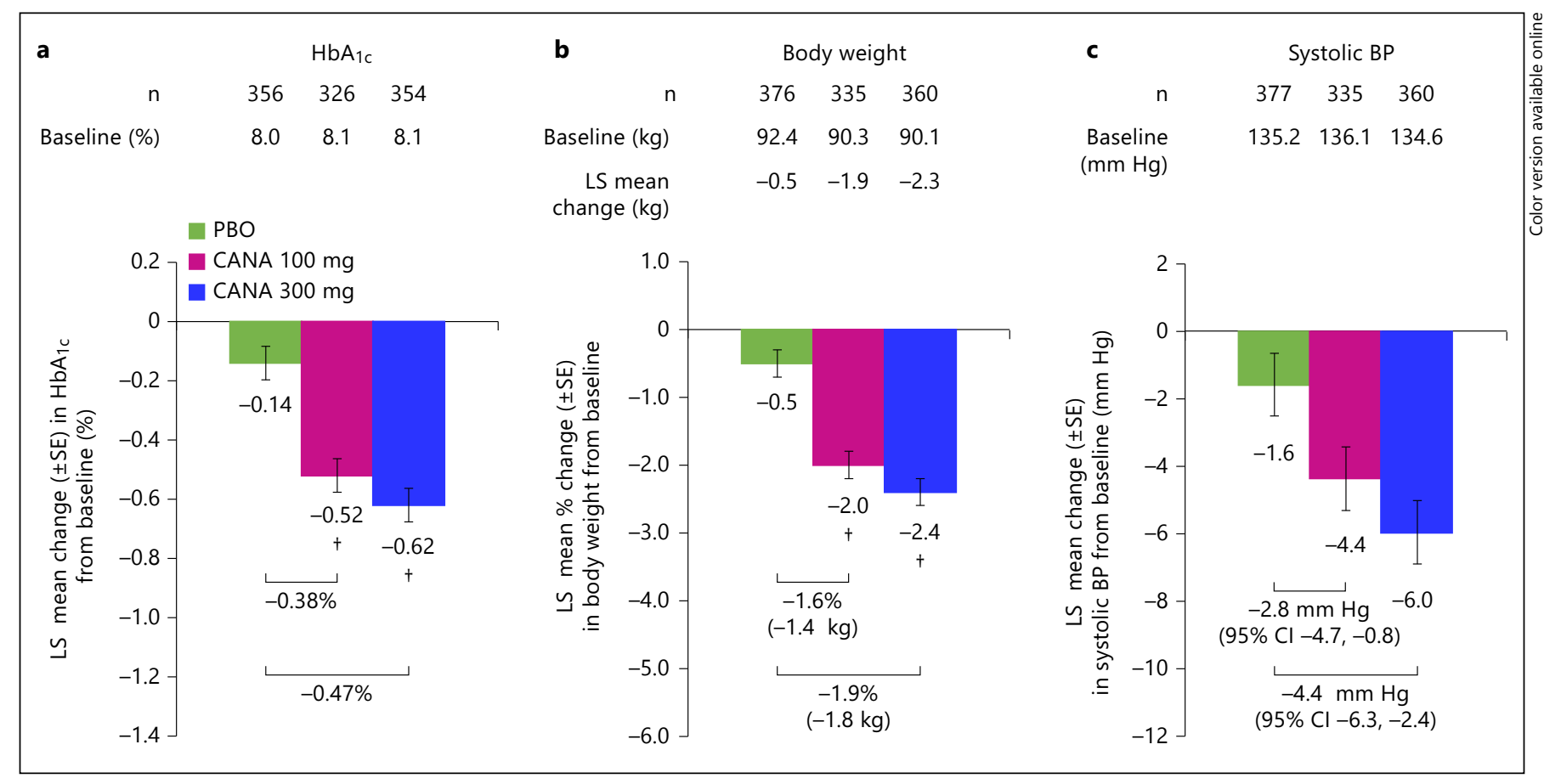

Fig. 1. Changes in $(\mathbf{a}) \mathrm{HbA}_{1 c}$, (b) body weight, and (c) systolic $\mathrm{BP}$ for the overall stage $3 \mathrm{CKD}$ population. $\mathrm{SE}=\mathrm{Standard}$ error; $\mathrm{PBO}=$ placebo; CANA = canagliflozin. Note: Statistical comparison for changes in systolic BP with CANA 100 and 300 mg vs. PBO not performed (not pre-specified). ${ }^{\dagger} \mathrm{p}<0.001$ vs. $\mathrm{PBO}$.

similar placebo-subtracted LS mean changes $(95 \% \mathrm{CI})$ of $-0.31 \%(-0.44,-0.19)$ and $-0.41 \%(-0.53,-0.28)$ with canagliflozin 100 and $300 \mathrm{mg}$, respectively; $<<0.001$. The proportion of subjects achieving $\mathrm{HbA}_{1 \mathrm{c}}<7.0 \%$ was higher with canagliflozin 100 and $300 \mathrm{mg}$ compared with placebo $(24.5,31.9$, and $17.4 \%$, respectively; $\mathrm{p}<0.001$ for canagliflozin $300 \mathrm{mg}$ vs. placebo). Canagliflozin 100 and $300 \mathrm{mg}$ were also associated with reductions in FPG relative to placebo (LS mean differences $(95 \% \mathrm{CI})$ of -1.1 $\mathrm{mmol} / \mathrm{l}(-1.4,-0.7)$ and $-1.2 \mathrm{mmol} / \mathrm{l}(-1.6,-0.9)$, respectively; $-18.8 \mathrm{mg} / \mathrm{dl}(-25.4,-12.4)$ and $-22.0 \mathrm{mg} / \mathrm{dl}(-28.4$, $-15.6)$, respectively; $\mathrm{p}<0.001)$.

There is no formal comparison of the glucose-lowering effect of canagliflozin between those with an eGFR $>60 \mathrm{ml} / \mathrm{min} / 1.73 \mathrm{~m}^{2}$ and those with stage $3 \mathrm{CKD}$. Glycemic efficacy, however, was demonstrated in subjects with CKD stage 3 renal disease (fig. 2), albeit with a lesser extent of glucose lowering than seen in subjects with stages 1 or 2 CKD. Nonetheless, canagliflozin got more subjects with stage $3 \mathrm{CKD}$ to the glycemic goal $\left(\mathrm{HbA}_{1 \mathrm{c}}<7 \%\right)$. The changes in $\mathrm{HbA}_{1 \mathrm{c}}$ are not confounded since these patients did not have anemia given baseline hemoglobin values $13.45,13.44$ and $13.54 \mathrm{~g} / \mathrm{dl}$ in the placebo, canagliflozin 100 - and 300-mg groups, respectively.
Body weight was significantly reduced in the overall population of subjects with stage $3 \mathrm{CKD}$ with canagliflozin 100 and $300 \mathrm{mg}$ compared with placebo (LS mean (placebo-subtracted) differences $(95 \% \mathrm{CI})$ of $-1.6 \%$ $(-2.0,-1.1)$ and $-1.9 \%(-2.3,-1.5)$, respectively; $-1.4 \mathrm{~kg}$ $(-1.8,-1.0)$ and $-1.8 \mathrm{~kg}(-2.1,-1.4)$, respectively; $\mathrm{p}<$ 0.001; fig. 1b). Canagliflozin 100 and $300 \mathrm{mg}$ were also associated with reductions in systolic BP relative to placebo (LS mean differences (95\% CI) of $-2.8 \mathrm{~mm} \mathrm{Hg}(-4.7$, $-0.8)$ and $-4.4 \mathrm{~mm} \mathrm{Hg}(-6.3,-2.4)$, respectively; fig. 1c). Generally, only minimal changes in fasting plasma lipids were observed with canagliflozin 100 and 300 mg compared with placebo (online suppl. table 2).

\section{Stage $3 a$ CKD Subgroup}

In the subgroup of subjects with stage $3 \mathrm{a} C K D$, placebo-subtracted LS mean reductions $(95 \% \mathrm{CI})$ in $\mathrm{HbA}_{1 \mathrm{c}}$ were $-0.47 \%(-0.61,-0.32)$ and $-0.52 \%(-0.67,-0.38)$ with canagliflozin 100 and $300 \mathrm{mg}$, respectively (online suppl. table 3). The proportion of subjects achieving $\mathrm{HbA}_{1 \mathrm{c}}<7.0 \%$ was $26.0,32.8$ and $19.4 \%$ with canagliflozin 100 and $300 \mathrm{mg}$ and placebo, respectively. Placebo-subtracted LS mean reductions (95\% CI) in FPG were also seen with canagliflozin $100 \mathrm{mg}(-1.2 \mathrm{mmol} / \mathrm{l}(-1.6,-0.8)$; 
Fig. 2. Comparison of placebo-subtracted effect of canagliflozin in people with stages 1 and 2 CKD versus stage 3 CKD. Data taken from online supplementary table 3 and metformin add-on study in normal subjects.

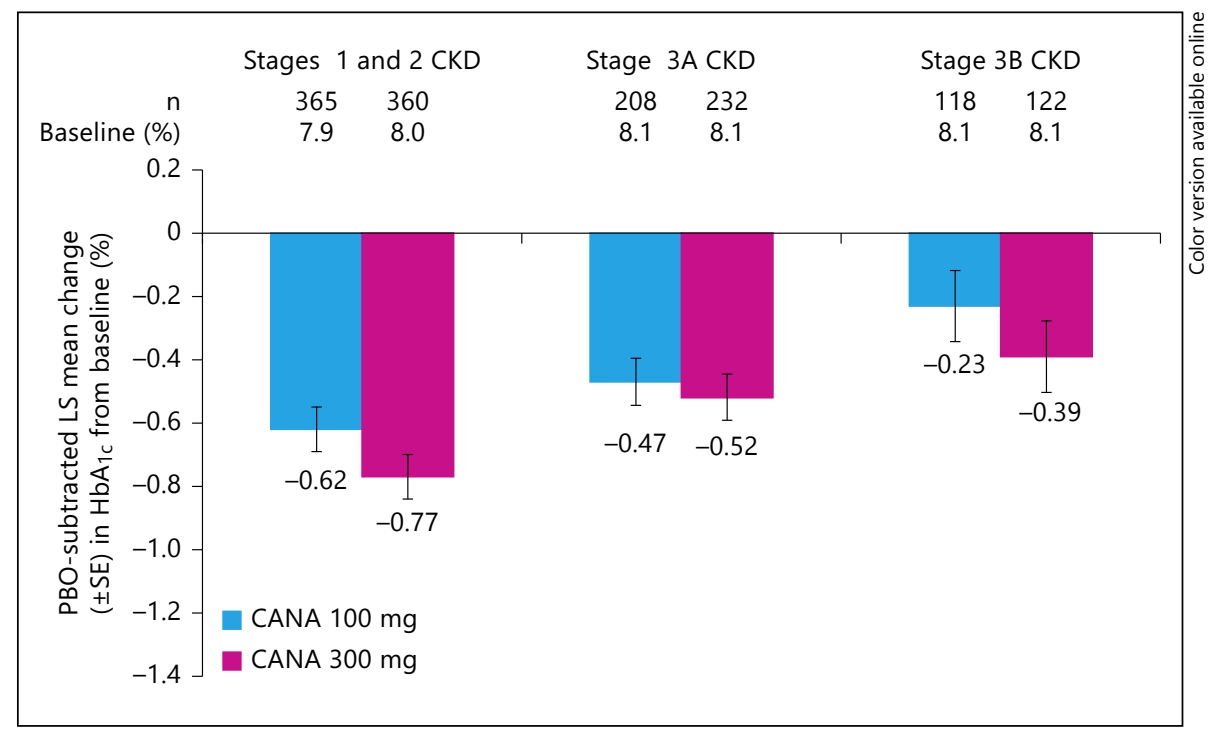

$-21.8 \mathrm{mg} / \mathrm{dl}(-29.4,-14.2))$ and $300 \mathrm{mg}(-1.3 \mathrm{mmol} / \mathrm{l}$ $(-1.7,-0.9) ;-23.0 \mathrm{mg} / \mathrm{dl}(-30.4,-15.6))$.

Placebo-subtracted LS mean percent reductions (95\% $\mathrm{CI})$ in body weight were $-1.8 \%(-2.3,-1.2)$ and $-2.0 \%$ $(-2.5,-1.5)$ with canagliflozin 100 and $300 \mathrm{mg}$, respectively (online suppl. table 3). Placebo-subtracted LS mean reductions $(95 \% \mathrm{CI})$ in systolic BP of $-1.8 \mathrm{~mm} \mathrm{Hg}(-4.1$, $0.5)$ and $-4.3 \mathrm{~mm} \mathrm{Hg}(-6.5,-2.0)$ with canagliflozin 100 and $300 \mathrm{mg}$, respectively, were seen in stage $3 \mathrm{a}$ CKD subjects (online suppl. table 3 ). Changes in fasting plasma lipids were generally similar in the stage $3 a$ CKD subgroup compared with the overall population, with the exception of larger percent increases in LDL-C with canagliflozin versus placebo in this subgroup (online suppl. table 4).

\section{Stage $3 b$ CKD Subgroup}

Placebo-subtracted LS mean reductions (95\% CI) in $\mathrm{HbA}_{1 \mathrm{c}}$ in the stage $3 \mathrm{~b}$ CKD subgroup were $-0.23 \%(-0.45$, $-0.01)$ and $-0.39 \%(-0.61,-0.17)$ with canagliflozin 100 and $300 \mathrm{mg}$, respectively. With canagliflozin 100 and 300 $\mathrm{mg}$ and placebo, $22.0,30.3$ and $13.0 \%$ of subjects, respectively, achieved $\mathrm{HbA}_{1 \mathrm{c}}<7.0 \%$. Reductions in FPG were observed with canagliflozin 100 and $300 \mathrm{mg}$ relative to placebo (LS mean differences $(95 \% \mathrm{CI}$ ) of $-0.7 \mathrm{mmol} / \mathrm{l}$ $(-1.4,-0.02)$ and $-1.1 \mathrm{mmol} / \mathrm{l}(-1.8,-0.4)$, respectively; $-12.8 \mathrm{mg} / \mathrm{dl}(-25.2,-0.4)$ and $-19.6 \mathrm{mg} / \mathrm{dl}(-32.1,-7.2)$, respectively).

Canagliflozin 100 and $300 \mathrm{mg}$ were associated with reductions in body weight compared with placebo (placebo-subtracted LS mean percent reductions $(95 \% \mathrm{CI})$ of $-1.2 \%(-1.9,-0.5)$ and $-1.8 \%(-2.5,-1.1)$, respectively; online suppl. table 3). Placebo-subtracted LS mean reductions (95\% CI) in systolic BP with canagliflozin 100 and $300 \mathrm{mg}$ were similar in the stage $3 \mathrm{~b}$ CKD subgroup $(-4.8$ $\mathrm{mm} \mathrm{Hg}(-8.5,-1.2)$ and $-4.9 \mathrm{~mm} \mathrm{Hg}(-8.5,-1.2)$, respectively; online suppl. table 3) compared with the overall population. Compared to placebo, both doses of canagliflozin showed reductions in LDL-C, LDL-C/HDL-C ratio, and non-HDL-C and increases in HDL-C. A relative decrease in triglycerides was seen with canagliflozin $100 \mathrm{mg}$ and an increase with canagliflozin $300 \mathrm{mg}$ (online suppl. table 4).

\section{Safety and Tolerability}

There was a higher incidence of AEs in those taking canagliflozin compared with placebo in the overall population as well as the stage $3 \mathrm{a}$ and $3 \mathrm{~b}$ CKD subgroups (table 3 and online suppl. table 5), however there were more serious $\mathrm{AEs}$ in the placebo group. In general, more subjects receiving canagliflozin $300 \mathrm{mg}$ had to discontinue the drug due to AEs compared to those receiving canagliflozin $100 \mathrm{mg}$ and placebo. In subjects with stage $3 \mathrm{~b} C K D$, however, AE-related discontinuation rates were higher in both canagliflozin dose groups compared with placebo (online suppl. table 5). The higher rate of discontinuation in those receiving $300 \mathrm{mg}$ was primarily related to AEs associated with reduced intravascular volume such as postural dizziness and hypotension as well as early and reversible reductions in eGFR.

In the overall CKD cohort, the incidence of AEs related to osmotic diuresis, including increased urine output and/ or frequency, and thirst, was similar across groups, and 
Table 3. Summary of overall safety and selected AEs (total stage 3 CKD cohort) ${ }^{\mathrm{a}}$

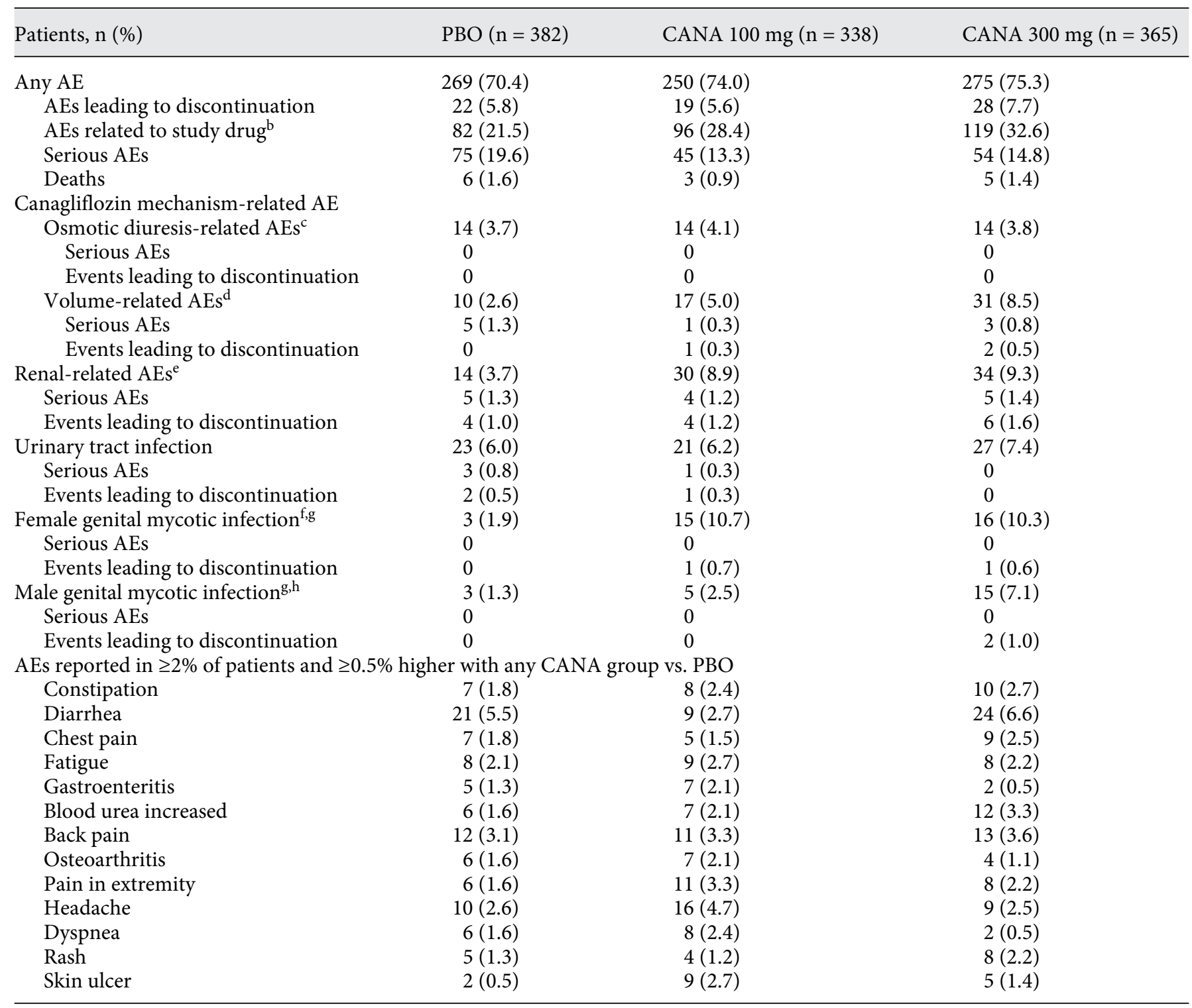

PBO = Placebo; CANA = canagliflozin.

${ }^{a}$ All AEs are reported for regardless of rescue medication. ${ }^{b}$ Possibly, probably, or very likely related to study drug, as assessed by investigators. ${ }^{c}$ Including micturition urgency, nocturia, pollakiuria, polyuria, urine output increased, dry mouth, and thirst. ${ }^{\mathrm{d}}$ Including dehydration, dizziness postural, hypotension, orthostatic hypotension, presyncope, and syncope. ${ }^{\mathrm{I}}$ Including blood creatinine increased, GFR decreased, oliguria, renal failure, renal failure acute, and renal impairment. ${ }^{\mathrm{f}} \mathrm{PBO}, \mathrm{n}=156$; CANA $100 \mathrm{mg}, \mathrm{n}=140$; CANA 300 $\mathrm{mg}, \mathrm{n}=155 .^{\mathrm{g}} \mathrm{AE}$ included in the grouped terms are not reported. ${ }^{\mathrm{h}} \mathrm{PBO}, \mathrm{n}=226$; CANA $100 \mathrm{mg}, \mathrm{n}=198 ; \mathrm{CANA} 300 \mathrm{mg}, \mathrm{n}=210$.

did not lead to study discontinuation. Reduced intravascular volume-related AEs, such as postural dizziness and orthostatic hypotension, were seen more frequently in the canagliflozin 100- and 300-mg groups compared with the placebo group. The incidence of urinary tract infections (UTIs) was slightly higher with canagliflozin $300 \mathrm{mg}$ ver- sus canagliflozin $100 \mathrm{mg}$ and placebo, without an observed increase in rate of upper UTIs across groups. An increased incidence of genital mycotic infections in males and females was seen with canagliflozin versus placebo; these AEs generally did not lead to study discontinuation. No notable differences in the incidence of these specific 
Fig. 3. Changes in eGFR among all stage 3 CKD participants. $\mathrm{PBO}=$ Placebo CANA $=$ canagliflozin; SE = standard error. Note: Data are reported regardless of rescue medication and up to within 2 days after the last dose of study drug.

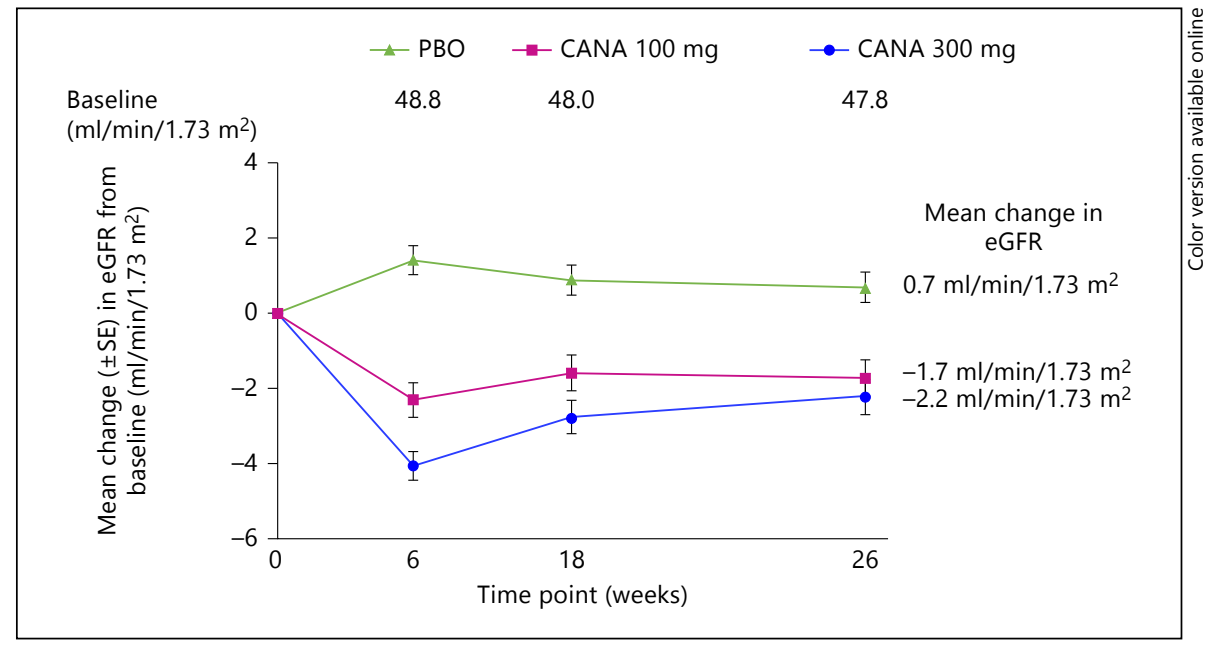

AEs from placebo were seen in subjects with stage $3 \mathrm{a}$ CKD. In subjects with stage $3 \mathrm{~b} C K D$, however, there was a higher incidence of side effects related to volume depletion and UTIs in the canagliflozin 300-mg group (online suppl. table 5) compared with the overall cohort.

\section{Hypoglycemia}

The incidence and severity of hypoglycemia varied depending on background AHA therapy. Of the $88.2 \%$ of subjects in the overall population treated with insulin and/or a sulfonylurea, 41.9 and $43.8 \%$ in the canagliflozin 100 - and 300-mg groups, respectively, experienced hypoglycemia episodes documented by decreases in plasma glucose to $\leq 3.9 \mathrm{mmol} / \mathrm{l}(70 \mathrm{mg} / \mathrm{dl})$, as compared to $29.2 \%$ in the placebo group. There were 20 subjects who experienced severe hypoglycemia episodes $(4$ (1.2\%) with placebo, $9(3 \%)$ with canagliflozin $100 \mathrm{mg}$, and $7(2.2 \%)$ with canagliflozin $300 \mathrm{mg}$ ). Of those who were not on insulin and/or a sulfonylurea, the incidence of hypoglycemia was low, with documented (based on plasma glucose) hypoglycemia reported in 1 patient (2\%) in the placebo group, $3(8.1 \%)$ in the canagliflozin $100-\mathrm{mg}$ group, and $1(2.4 \%)$ in the canagliflozin 300-mg group. There were no severe hypoglycemic episodes among subjects not taking insulin and/or a sulfonylurea.

\section{Assessment of Kidney Function}

Changes in eGFR with canagliflozin in the overall cohort demonstrated a small initial decline followed by return towards trend to baseline (fig. 3) (the changes in eGFR for stages $3 \mathrm{a}$ and $3 \mathrm{~b}$ CKD are provided in online suppl. fig. 1). These changes suggest an early hemodynamic effect, seen within days of treatment followed by attenuation over time. When endpoint analyses were performed in the overall population, mean eGFR decreased by -1.7 and $-2.2 \mathrm{ml} / \mathrm{min} / 1.73 \mathrm{~m}^{2}$ in those treated with canagliflozin 100 and $300 \mathrm{mg}$, respectively, while it rose by $0.7 \mathrm{ml} / \mathrm{min} / 1.73 \mathrm{~m}^{2}$ in the placebo group. Similar mean changes were seen with canagliflozin 100 and $300 \mathrm{mg}$ compared with placebo at week 26 in the stage $3 \mathrm{a}$ CKD subgroup $\left(-1.4,-2.3\right.$, and $1.0 \mathrm{ml} / \mathrm{min} / 1.73 \mathrm{~m}^{2}$, respectively) and the stage $3 \mathrm{~b}$ CKD subgroup $(-2.4,-2.1$, and 0.01 $\mathrm{ml} / \mathrm{min} / 1.73 \mathrm{~m}^{2}$, respectively).

In the dedicated study of subjects with stage $3 \mathrm{CKD}$ (table 1), 29 subjects with macroalbuminuria at baseline ( $>300 \mu \mathrm{g} / \mathrm{mg} ; 14$ in the placebo group, 7 in the canagliflozin 100-mg group and 8 in the canagliflozin $300-\mathrm{mg}$ group), showed mean percent reductions (SD) in albuminuria of -19.6 (47.3), -53.1 (17.4), and -44.7 (36.0)\%, respectively.

The incidence of kidney-associated AEs (e.g. increased serum creatinine, decreased eGFR, renal failure, and kidney function impairment) were higher with canagliflozin than with placebo (table 3 ) and generally higher in those with stage $3 \mathrm{~b}$ CKD (online suppl. table 5). In the overall population, the most common specific terms for renal AEs in the pooled canagliflozin group were blood creatinine increased (5.3\%), renal impairment (2.4\%), and GFR decreased (1.3\%).

\section{Changes in Serum Potassium}

No significant changes in mean serum potassium were seen with canagliflozin 100 and $300 \mathrm{mg}$ compared with placebo in the overall population $(-0.01,0.07$, and 0.02 $\mathrm{mEq} / \mathrm{l}(\mathrm{mmol} / \mathrm{l})$, respectively), the stage $3 \mathrm{a}$ CKD subgroup $(0.05,0.10$, and $0 \mathrm{mEq} / \mathrm{l}(\mathrm{mmol} / \mathrm{l})$, respectively), or 
the stage $3 \mathrm{~b}$ CKD subgroup $(-0.12,0.02$, and $0.07 \mathrm{mEq} / \mathrm{l}$ ( $\mathrm{mmol} / \mathrm{l})$, respectively). Based on any post-baseline value, the proportion of subjects experiencing increased serum potassium above the upper limit of normal and $>15 \%$ increase from baseline with placebo, canagliflozin 100 and $300 \mathrm{mg}$ was $7.9,7.2$, and $12.0 \%$, respectively, in the overall population; 5.5, 5.2, and 9.1\%, respectively, in the stage 3a CKD subgroup, and 13.5, 10.9, and $17.4 \%$, respectively, in the stage $3 \mathrm{~b}$ CKD subgroup. When assessed based on the last post-baseline value, fewer subjects had an increase in serum potassium above the upper limit of nor$\mathrm{mal}$ and $>15 \%$ increase from baseline in the overall population $(3.0,1.8$ and $3.1 \%$, in the placebo, canagliflozin 100 - and 300-mg groups, respectively), the stage $3 \mathrm{a}$ CKD subgroup (3.1, 1.9, and $1.7 \%$, respectively), and the stage $3 \mathrm{~b}$ CKD subgroup $(2.7,1.7$, and $5.8 \%$, respectively). Few subjects had any post-baseline potassium elevations that were $\geq 6.5 \mathrm{mEq} / \mathrm{l}$ with canagliflozin 100 and $300 \mathrm{mg}$ and placebo in the overall population $(1.1,0.9$, and $2.3 \%$, respectively), the stage $3 \mathrm{a}$ CKD subgroup $(0.8,0$, and $1.3 \%$, respectively), and the stage $3 \mathrm{~b}$ CKD subgroup $(1.8,2.5$, and $4.1 \%$, respectively).

\section{Phosphate}

Using post-baseline data the proportion of subjects with increasing serum phosphate levels above the upper limit of normal and $>25 \%$ increase from baseline with placebo, canagliflozin 100 and $300 \mathrm{mg}$ was $0.3,2.7$, and $5.1 \%$, respectively. When assessed based on the last post-baseline value, fewer subjects had an increase in serum phosphate above the upper limit of normal and $>25 \%$ increase from baseline in the overall population $(0,0.6$ and $1.4 \%$, in the placebo, canagliflozin 100- and 300-mg groups, respectively).

Serious AEs related to elevated potassium were reported in 3 subjects ( 1 with canagliflozin $100 \mathrm{mg}$ and 2 with canagliflozin $300 \mathrm{mg}$ ), all receiving multiple antihypertensive agents affecting potassium homeostasis. All three serious events coincided with an acute event, e.g. renal failure, and two led to study discontinuation, both with canagliflozin $300 \mathrm{mg}$.

\section{Discussion}

We evaluated the effects of canagliflozin in a pooled analysis of four randomized, placebo-controlled trials involving T2DM subjects with stage $3 \mathrm{CKD}$. Canagliflozin improved glycemic control in subjects with stage $3 \mathrm{CKD}$, with a greater effect observed in subjects with stage $3 \mathrm{a}$ CKD. Mean reductions in stage $3 \mathrm{~b}$ CKD were smaller, however, still more subjects achieved an $\mathrm{HbA}_{1 \mathrm{c}}$ goal of $<7.0 \%$ compared to placebo.

Canagliflozin $100 \mathrm{mg}$ once daily is recommended for use in management of T2DM in subjects with an eGFR of 45 to $<60 \mathrm{ml} / \mathrm{min} / 1.73 \mathrm{~m}^{2}$ [20]. In the USA, canagliflozin $100 \mathrm{mg}$ can be initiated in subjects with an eGFR $\geq 45 \mathrm{ml} /$ $\min / 1.73 \mathrm{~m}^{2}$. In Europe, patients must have baseline eGFR $\geq 60 \mathrm{ml} / \mathrm{min} / 1.73 \mathrm{~m}^{2}$ to initiate canagliflozin therapy; however, patients whose eGFR falls persistently to $<60$ $\mathrm{ml} / \mathrm{min} / 1.73 \mathrm{~m}^{2}$ can continue treatment with canagliflozin $100 \mathrm{mg}$ unless eGFR falls below $45 \mathrm{ml} / \mathrm{min} / 1.73 \mathrm{~m}^{2}$.

The mechanism of canagliflozin action results in an osmotic diuresis and caloric loss, which contributes to both weight loss and $\mathrm{BP}$ reduction. $\mathrm{BP}$ control is a major concern in patients with stage $3 \mathrm{CKD}$ and hypertension is one of the most important risk factors that influences $\mathrm{CKD}$ progression, as well as the risk of cardiovascular events. Canagliflozin reduces BP in those with stage 3 $\mathrm{CKD}$, further enhancing systolic BP reduction by an additional 3-7 $\mathrm{mm} \mathrm{Hg}$ on top of renin-angiotensin system blocking therapy and diuretics [21].

Reduced intravascular volume and decreased eGFR were also observed in patients with stage $3 \mathrm{CKD}$, mostly within the first months of treatment and, in a small subgroup, resulted in drug discontinuation or other antihypertensive drug modification. A dose-dependent increase in AEs related to reduced intravascular volume was seen with canagliflozin in the CKD cohort. Initial declines in eGFR of $10-15 \%$ trended toward baseline after about 6 weeks. These changes are likely due to hemodynamic effects on the kidney, and do not suggest progressive renal injury in subjects with stage 3 CKD. By blocking SGLT2dependent glucose reabsorption, SGLT2 inhibitors such as canagliflozin are expected to increase the sodium concentration in the proximal convoluted tubule, thereby activating tubuloglomerular feedback, leading to a decrease in hyperfiltration in preclinical models and clinical studies of diabetes [22,23]. Small increases in LDL-C have been associated with canagliflozin treatment $[6-8,10-13,18]$. The mechanism for this is not completely understood. In the current analysis, percent increases in LDL-C were seen with canagliflozin 100 and $300 \mathrm{mg}$ compared with placebo in the overall population and the stage $3 \mathrm{a}$ CKD subgroup, but decreases in LDL-C were seen in the stage $3 \mathrm{~b}$ CKD subgroup. This is likely related to the greater increase in LDL$\mathrm{C}$ in the placebo group in the stage $3 \mathrm{~b}$ CKD subgroup.

An increase in UTIs and genital mycotic infections has been previously reported [24]. In the overall population, the incidence of UTIs was slightly higher with canagliflozin $300 \mathrm{mg}$ versus canagliflozin $100 \mathrm{mg}$ and placebo;
Yamout et al. 
there was no difference across groups in upper UTIs. Incidences of genital mycotic infections in males and females were higher with both doses of canagliflozin compared with placebo. However, these AEs were mild to moderate in intensity, generally did not lead to study drug discontinuation or interruption, and were treated by either a healthcare professional or by the patient with either topical or oral antifungal agents. The incidence of fracture AEs was not assessed in the current analysis, but a previous study in subjects with eGFR $\geq 30$ and $<50 \mathrm{ml} /$ $\min / 1.73 \mathrm{~m}^{2}$ showed a low incidence of fractures with canagliflozin 100 and $300 \mathrm{mg}$ and placebo, with no imbalance between groups [13].

The incidence of serum potassium elevation was increased with canagliflozin $300 \mathrm{mg}$ compared with placebo with no incremental changes observed with canagliflozin $100 \mathrm{mg}$, the dosage indicated in patients with stage $3 \mathrm{a} C \mathrm{CK}$ in the USA. In general, elevations in potassium were transient and did not require specific treatment. Significant elevations in serum potassium were uncommon and more frequently seen in patients with stage $3 \mathrm{~b} C \mathrm{CKD}$ who received either the 300-mg dose, had elevated serum potassium concentrations prior to treatment, and/or were on multiple medications that reduce potassium excretion. However, there was no notable increase in incidence of hyperkalemia, i.e. serum potassium $\geq 6.5 \mathrm{mEq} / 1$ with canagliflozin, even in the stage $3 \mathrm{~b}$ CKD subgroup. Changes in potassium with canagliflozin did not appear related to changes in eGFR, blood urea nitrogen, or hemoglobin or to reduced intravascular volume. Of note, there were no other major electrolyte abnormalities associated with use of this drug.

There are limitations to the analyses presented in that they represent pooled data and are drawn from cohorts that do not fully represent the cross section of ethnic groups with diabetic kidney disease, i.e. AmericanIndians, Asian-Pacific Islanders and relatively low numbers of African-Americans and Hispanics. Nevertheless, the data are consistent in both safety and efficacy and there is no mechanistic reason to think the response would be different in these underrepresented groups.

In summary, the oral treatment options for T2DM patients with stage $3 \mathrm{a}$ CKD are limited to reduced doses of either metformin, peroxisome proliferator-activated receptor- $\gamma$ agents, or dipeptidyl peptidase 4 inhibitors [25]. Insulin and sulfonylureas may lead to weight gain, edema, or hypoglycemia. Certain SGLT2 inhibitors, namely canagliflozin, provide a new treatment option to help achieve glycemic control in T2DM patients with stage 3a CKD. The medication is well tolerated overall with the most common AEs relating to genital mycotic infections and enhanced risk of intravascular volume reduction, the latter also occurring in patients aged $\geq 75$ years, and on loop diuretics. The effects of canagliflozin on CKD progression in man is currently being studied in the Canagliflozin and Renal Events in Diabetes with Established Nephropathy Clinical Evaluation Trial (CREDENCE) [26]. The results will provide the answer as to whether SGLT2 inhibition slows nephropathy progression.

\section{Disclosure Statement}

The primary (H.Y.) and senior authors (G.B.) as well as (V.P., M.D., V.W. and D.D.Z.) received no compensation for this work. G.B., V.P., D.D.Z., M.D. and V.W. are consultants for Janssen Pharma. The remaining authors are employees of Janssen Pharma.

\section{References}

1 Inzucchi SE, Bergenstal RM, Buse JB, Diamant M, Ferrannini E, Nauck M, Peters AL, Tsapas A, Wender R, Matthews DR: Management of hyperglycemia in type 2 diabetes: a patientcentered approach: position statement of the American Diabetes Association (ADA) and the European Association for the Study of Diabetes (EASD). Diabetes Care 2012;35:1364-1379.

$\checkmark 2$ Koro CE, Lee BH, Bowlin SJ: Antidiabetic medication use and prevalence of chronic kidney disease among patients with type $2 \mathrm{di}$ abetes mellitus in the United States. Clin Ther 2009;31:2608-2617.

$>3$ Reilly JB, Berns JS: Selection and dosing of medications for management of diabetes in patients with advanced kidney disease. Semin Dial 2010;23:163-168. $\checkmark 4$ Bailey CJ: Renal glucose reabsorption inhibitors to treat diabetes. Trends Pharmacol Sci 2011;32:63-71.

5 Nair S, Wilding JP: Sodium glucose co-transporter 2 inhibitors as a new treatment for diabetes mellitus. J Clin Endocrinol Metab 2010; 95:34-42.

6 Bode B, Stenlof K, Sullivan D, Fung A, Usiskin $\mathrm{K}$ : Efficacy and safety of canagliflozin treatment in older subjects with type 2 diabetes mellitus: a randomized trial. Hosp Pract (1995) 2013;41:72-84.

$>7$ Cefalu WT, Leiter LA, Yoon KH, Arias P, Niskanen L, Xie J, Balis DA, Canovatchel W, Meininger G: Efficacy and safety of canagliflozin versus glimepiride in patients with type 2 diabetes inadequately controlled with metformin (CANTATA-SU): 52-week results from a randomised, double-blind, phase 3 non-inferiority trial. Lancet 2013;382:941950.

-8 Lavalle-Gonzalez FJ, Januszewicz A, Davidson J, Tong C, Qiu R, Canovatchel W, Meininger G: Efficacy and safety of canagliflozin compared with placebo and sitagliptin in patients with type 2 diabetes on background metformin monotherapy: a randomised trial. Diabetologia 2013;56:2582-2592.

9 Rosenstock J, Aggarwal N, Polidori D, Zhao Y, Arbit D, Usiskin K, Capuano G, Canovatchel W: Dose-ranging effects of canagliflozin, a sodium-glucose co-transporter 2 inhibitor, as add-on to metformin in subjects with type 2 diabetes. Diabetes Care 2012;35:1232-1238. 
10 Schernthaner G, Gross JL, Rosenstock J, Guarisco M, Fu M, Yee J, Kawaguchi M, Canovatchel W, Meininger G: Canagliflozin compared with sitagliptin for patients with type 2 diabetes who do not have adequate glycemic control with metformin plus sulfonylurea: a 52-week randomized trial. Diabetes Care 2013;36:2508-2515.

11 Stenlof K, Cefalu WT, Kim KA, Alba M, Usiskin K, Tong C, Canovatchel W, Meininger G: Efficacy and safety of canagliflozin monotherapy in subjects with type 2 diabetes mellitus inadequately controlled with diet and exercise. Diabetes Obes Metab 2013;15:372-382.

12 Wilding JP, Charpentier G, Hollander P, Gonzalez-Galvez G, Mathieu C, Vercruysse F, Usiskin K, Law G, Black S, Canovatchel W, Meininger G: Efficacy and safety of canagliflozin in patients with type 2 diabetes mellitus inadequately controlled with metformin and sulphonylurea: a randomised trial. Int J Clin Pract 2013;67:1267-1282.

13 Yale JF, Bakris G, Cariou B, Yue D, DavidNeto E, Xi L, Figueroa K, Wajs E, Usiskin K, Meininger G: Efficacy and safety of canagliflozin in subjects with type 2 diabetes and chronic kidney disease. Diabetes Obes Metab 2013; 15:463-473.

14 Devineni D, Morrow L, Hompesch M, Skee D, Vandebosch A, Murphy J, Ways K, Schwartz S: Canagliflozin improves glycaemic control over 28 days in subjects with type 2 diabetes not optimally controlled on insulin. Diabetes Obes Metab 2012;14:539-545.
5 Polidori D, Sha S, Ghosh A, Plum-Morschel L, Heise T, Rothenberg P: Validation of a novel method for determining the renal threshold for glucose excretion in untreated and canagliflozin-treated subjects with type 2 diabetes mellitus. J Clin Endocrinol Metab 2013; 98:E867-E871.

16 Sha S, Devineni D, Ghosh A, Polidori D, Chien S, Wexler D, Shalayda K, Demarest K, Rothenberg P: Canagliflozin, a novel inhibitor of sodium glucose co-transporter 2, dose dependently reduces calculated renal threshold for glucose excretion and increases urinary glucose excretion in healthy subjects. Diabetes Obes Metab 2011;13:669-672.

17 Levey AS, de Jong PE, Coresh J, El NM, Astor BC, Matsushita K, Gansevoort RT, Kasiske BL, Eckardt KU: The definition, classification, and prognosis of chronic kidney disease: a KDIGO Controversies Conference report. Kidney Int 2011;80:17-28.

18 Stenlof K, Cefalu WT, Kim KA, Jodar E, Alba M, Edwards R, Tong C, Canovatchel W, Meininger G: Long-term efficacy and safety of canagliflozin monotherapy in patients with type 2 diabetes inadequately controlled with diet and exercise: findings from the 52-week CANTATA-M study. Curr Med Res Opin 2014;30:163-175.

19 Neal B, Perkovic V, de Zeeuw D, Mahaffey KW, Fulcher G, Stein P, Desai M, Shaw W, Jiang J, Vercruysse F, Meininger G, Matthews $\mathrm{D}$ : Rationale, design, and baseline characteristics of the Canagliflozin Cardiovascular Assessment Study (CANVAS) - a randomized placebo-controlled trial. Am Heart J 2013; 166:217-223.
20 Invokana $^{\circledR} 100 \mathrm{mg}$ film-coated tablets. Summary of product characteristics (2.12.20132.4.2014). High Wycombe, Janssen-Cilag, 2014.

21 Oliva RV, Bakris GL: Blood pressure effects of sodium-glucose co-transport 2 (SGLT2) inhibitors. J Am Soc Hypertens 2014;8:330339.

22 Cherney DZ, Perkins BA, Soleymanlou N, Maione M, Lai V, Lee A, Fagan NM, Woerle HJ, Johansen OE, Broedl UC, von EM: Renal hemodynamic effect of sodium-glucose cotransporter 2 inhibition in patients with type 1 diabetes mellitus. Circulation 2014;129: 587-597.

23 Thomson SC, Rieg T, Miracle C, Mansoury H, Whaley J, Vallon V, Singh P: Acute and chronic effects of SGLT2 blockade on glomerular and tubular function in the early diabetic rat. Am J Physiol Regul Integr Comp Physiol 2012;302:R75-R83.

24 Nicolle LE, Capuano G, Fung A, Usiskin K: Urinary tract infection in randomized phase III studies of canagliflozin, a sodium glucose co-transporter 2 inhibitor. Postgrad Med 2014;126:7-17.

25 Flynn C, Bakris GL: Noninsulin glucose-lowering agents for the treatment of patients on dialysis. Nat Rev Nephrol 2013;9:147-153.

26 CREDENCE Trial: 2014. http://www.clinical trials.gov/ct2/show/NCT02065791?term $=\mathrm{CR}$ EDENCE\&rank=1. 